\title{
A comunicação nas ciências da linguagem
}

$\frac{\text { Geraldo Carlos do Nascimento }}{\text { Universidade Tuiuti do Paraná/UTP }}$ 


\section{Resumo}

Este trabalho situa a questão da comunicação na sua vertente relacionada com as ciências da linguagem, que ganham corpo, embora suas origens remontem a Saussure, a partir do ensaio de Roman Jakobson, Linguistic and Poetics (1960), no qual é apresentado um esquema básico da comunicação. As fragilidades deste esquema, ainda vinculado às noções da sociologia funcionalista (Laswell/ Scharam), logo se fizeram notar, particularmente no que se refere à sua operacionalização; mas foi a partir de sua crítica, conforme se defende aqui, que a semiótica greimasiana pôde, ao articular comunicação e sentido, estabelecer bases mais consistentes para a discussão da noção de comunicação e se seu campo presumível.

\section{Palavras-chave}

comunicação, ciências da linguagem, semiótica greimasiana

\section{Abstract}

This work sets the question of communication in its versant related to the increasing language sciences, which origins date back to Saussure starting from Roman Jakobson's essay Linguistic and Poetics (1960), where a basic scheme of communication is presented. The fragility of this scheme, still linked to the functional sociology (Laswell/Scharam), was soon noticed, particularly when referring to its practicing; but it was from its critique, as defended here, that the Greimasian semiotics could establish more consistent basis to the discussion of the notion of communication and its assumed field, as articulating communication and meaning.

\section{Key words}

communication, language sciences, greimasian semiotics 


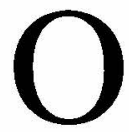

$S$ antecedentes do esquema da comunicação de Roman Jakobson, do qual partiremos para nossas investigações sobre a noção de comunicação ${ }^{1}$, podem ser encontrados de forma embrionária em Karl Bühler, que distinguia, na atividade lingüística, três funções inerentes à natureza da própria língua: a representação, a expressão e o apelo.

Cada uma dessas funç̃ões estabeleceria uma relação entre o signo lingüístico com uma das três instâncias extralíngüísticas requeridas em qualquer funcionamento da fala: a realidade (à qual se refere o signo), o sujeito destinador e o sujeito destinatário. A partir desse vínculo, Bühler define as funções da linguagem como: 1) expressiva, fundada no ponto de vista do destinador; 2) apelativa, no ponto de vista do destinatário; e 3) representativa, que remete ao referente ou ao seu contexto ${ }^{2}$.

Considerando as teorias em voga nas décadas de 50 e 60 entre engenheiros norte-americanos das telecomunicações e preocupado, basicamente, em dar conta dos fatores que envolvem o ato de comunicação ${ }^{3}$, Jakobson acrescenta mais três elementos a este

1. Este trabalho, desenvolvido a partir de um texto que apresentamos em nossa tese de doutorado (1997) e do qual preparamos uma versão a XXI Compós, realizado na Escola de Comunicação da Universidade Federal do Rio de Janeiro (ECO-RJ) em junho de 2002, situa a questão da comunicação na sua vertente relacionada com as ciências da.linguagem, que ganha corpo, embora suas origens remontem à Saussure, a partir do ensaio de Roman Jakobson Lingüística e Poética, publicado originalmente em 1960, em New York.

2. Jan Mukarovsky, na década de 30, também com base neste esquema de Bühler, distinguiu uma quarta função: a função estética, que estaria fundada no contexto e não na realidade do referente, como seria o caso específico da linguagem denotativa.

3. "A linguagem deve ser estudada em toda a variedade de suas funções. Antes de discutir a função poética, devemos definir-lhe o lugar entre as outras 
esquema, e os redefine uns em função dos outros, como convinha aos preceitos do emergente estruturalismo ${ }^{4}$, e seu esquema da comunicação passa a contar com seis elementos: o destinador, o destinatário, a mensagem (transmitida de um para outro), o contexto ou referente (verbal ou verbalizável), o código (mais ou menos comum aos atores da comunicação) e o contato (que repousa sobre o canal físico e/ou a uma conexão psicológica entre o destinador e o destinatário). Este último fator, Jakobson foi buscar nas concepções do antropólogo Malinowski ${ }^{5}$, já revisitado por Ogden e Richards (1923) em The Meaning of Meaning.

A cada um desses seis elementos, Jakobson fez corresponder uma função específica da linguagem. Assim, ao destinador o lingüista atribuiu a função emotiva (ou expressiva); ao destinatário, a função conativa (ou apelativa); à mensagem, a função poética; ao contexto ou referente, a função referencial; ao código, a função metalingüística; ao contato, a função fática; "mapeando", assim, o que podemos considerar os territórios implicitados pelos atos enunciativoscomunicacionais ${ }^{6}$.

Não obstante a larga difusão e grande prestígio alcançado por este esquema, suas fragilidades não tardaram a ser apontadas, particularmente pela semiótica emergente dos anos 70 , que nesta época centrava seus esforços com vistas a explicitar a produção do sentido, balizando-se pelo princípio da imanência prescrito por Hjelmslev, na instância do enunciado. Uma das primeiras fraquezas

funções da linguagem. Para se ter uma idéia geral dessas funções, é mister uma perspectiva sumária dos fatores constitutivos de todo processo lingüístico, de todo ato de comunicação verbal." (grifo nosso) (Jakobson, 1969: 122/123)

4. Será na análise da mensagem, local onde Jakobson detecta a incidência da função poética, que as ferramentas herdadas do estruturalismo lingüístico melhor dão sinais de sua eficácia, particularmente na correlação que o autor faz entre os eixos paradigmático e sintagmático com a metáfora e a metonímia, e que se poderia também vincular aos processos de condensação e deslocamento freudianos. Estes dispositivos seriam responsáveis pelo encadeamento dos discursos.

5. "Este pendor para o contacto ou, na designação de Malinowski, para a função fática, pode ser evidenciada por uma troca profusa de fórmulas ritualizadas, por diálogos inteiros cujo único propósito é prolongar a comunicação." (Jakobson, 1969: 126)

6. Até que ponto um ato enunciativo é já um ato de comunicação? Sem dúvida, esta é uma questão polêmica, mas acreditamos poder defender uma certa equivalência entre esses atos se formos além dos conteúdos cognitivos dos enun- 
apontadas seria a generalidade de tal esquema, que dificultaria o estabelecimento de uma taxionomia e de uma sintaxe adequadas. Além disso, o esquema guardaria um excessivo comprometimento com a comunicação verbal, uma vez que parece concernente tão só ao fazer informativo, articulável no vínculo destinador-destinatário, que mobilizariam nesta relação um fazer emissivo e um fazer receptivo, orientado no sentido linear da emissão para a recepção.

$\mathrm{Na}$ tentativa de escapar de uma concepção considerada demasiado mecanicista, determinada pelo modelo da informação, ou demasiado restritiva, presa aos parâmetros extralingüísticos, a semiótica greimasiana, por exemplo, procura situar esta noção-chave em contextos mais amplos, como o das atividades humanas em geral. Essas atividades ocorreriam em dois eixos principais: o eixo da produção, onde haveria uma ação visando diretamente às coisas e o homem transformaria o mundo dito natural, e o eixo da comunicação, no qual, por meio da ação do homem sobre outros homens, haveria a criação de relações intersubjetivas, fundadoras das sociedades e das culturas (Greimas/Courtés, 197977).

O conceito de troca, introduzido na antropologia social francesa desde que Marcel Mauss publicou Essais sur le Don, Forme Archaïque de l'Échange em meados dos anos $30^{8}$, recobre este segundo eixo, com o sentido de transferência de objetos ou como comunicação entre sujeitos. É baseando-se neste conceito que LéviStrauss $(1976 ; 31)$ distingue três dimensões dessas transferênciascomunicações: 1) as trocas de mulheres (estrutura do parentesco), 2) as trocas de bens e de serviços (estruturas econômicas) e 3) as trocas de mensagens (estruturas lingüísticas ou semióticas).

Do conceito de troca, consideram Greimas/Courtés,

dever-se-ia subtrair as conotações eufóricas que aludem à 'benevolência' universal dos homens no seu mútuo relacionamento, já que é difícil, senão impossível, estabelecer

ciados e considerarmos as relaçōes entre os actantes mobilizados.

7. Sémiotique - Dictionnaire Raisonné de la Théorie du Langage, Hachette, Paris, 1979, de Greimas e Courtés, foi traduzido para o português com o título Dicionário de Semiótica e editado pela Cultrix, s/d.

8. Ver "De Mauss a Claude Lévy-Strauss" (Merleau-Ponty; 1960). 
fronteiras entre as estruturas contratuais e polêmicas que presidem a comunicação. (Greimas/ Courtés,1979).

Assim, a abordagem propriamente semiótica da comunicação resta bem diferente das apresentadas pelas teorias econômicas ou pelas teorias da comunicação tradicionais, das quais o esquema aludido pode ser considerado representativo. Na medida em que a comunicação se situa entre sujeitos e na medida em que os valores investidos nos objetos postos em circulação (valores pragmáticos ou cognitivos, descritivos ou modais) são considerados constitutivos do ser do sujeito é evidente que o destinador e o destinatário não podem ser considerados meras abstrações, tratados como "posições vazias de emissor e de receptor, mas ao contrário como sujeitos competentes, pinçados num momento de seu devir, inscrito cada qual no seu próprio discurso."

Assim, segundo Greimas/Courtés

Compreende-se (...) porque um diálogo que aparece no interior do discurso narrativo parece fornecer uma representação mais correta do processo da comunicação do que um artefato construído a partir do esquema da comunicação extralingüistica. Nos propomos interpretar uma 'troca de mensagens', no plano semântico, pelo menos, como um discurso a duas ou mais vozes.

No entanto, essa "humanização" da comunicação não deixa de apresentar novas questões. Uma delas, acontece com a chamada "comunicação participativa", na qual, contrariamente ao que ocorre por ocasião da comunicação ordinária, "a atribuição de um objetovalor é concomitante a uma renúncia". Os discursos etnoliterários, filosóficos, jurídicos, por exemplo, apresentam estruturas de comunicação em que o destinador transcendente proporciona valores tanto modais (querer, dever, saber, poder) quanto descritivos (os bens materiais), sem a eles renunciar.

Caso que deve ser distinguido, conforme os autores do Dictionnaire chamam a atenção, daquele em que o fornecedor do 
saber que, por ocasião da comunicação, transmite um objeto cognitivo sem que seu próprio saber diminua. $O$ fenômeno se explica pelo fato de que o sujeito da enunciação é um ator sincrético que subsume os dois actantes, que são o enunciador e o enunciatário, ou, em outras palavras, que ele é seu próprio enunciatário e retoma, desse modo, aquilo que ele mesmo forneceu como enunciador ${ }^{9}$.

Não se pode, porém, reduzir a comunicação aos aspectos cognitivos. Se se enfoca a questão, por exemplo, em termos de "comunicação recebida" e de "comunicação assumida", como é o caso do "discurso psicanalítico que evidenciou o desvio que há entre a emissão e a recepção. Tudo se passa como se o receptor não pudesse entrar em plena posse do sentido a não ser dispondo de antemão de um querer e de um poder aceitar, ou seja, que já fosse determinado por uma competência receptiva". Em tal perspectiva, "se assumir a fala do outro seria nela acreditar, fazê-la assumir equivaleria a falar para ser acreditado". Daí a semiótica greimasiana considerar que a comunicação se aproxima muito mais de um fazer-crer (persuasão) e de um fazer-fazer (manipulação) do que de um fazer-saber, pressuposto fundante do esquema de comunicação tradicional.

Adotando essa postura, a semiótica põe em questão as teorias que concebem a comunicação como uma simples transmissão do saber, que passaria, em forma de mensagem, de uma instância emissora para uma instância receptora, mesmo que algumas delas, como a defendida por Jakobson, reconheçam que ocorrem nessa passagem coerções provinientes do canal de transmissão, do código convocado e do contexto.

Jacques Fontanille, por exemplo, pergunta como descrever a "comunicação" entre o pintor e seu espectador sem ter de sair dos limites do quadro ou ter de convocar os atores reais, de carne e osso, quando se adota a noção de "transmissão" de um saber do destinador para o destinatário. E ele próprio ensaia uma resposta:

Si on veut tenir compte des sujets d'énonciation tels qu'ils son inscrits dans les tableau-lui même, ou préssupposés par

9. Denomina-se enunciador o destinador implícito da enunciação. O enunciatário, por sua vez, corresponde ao destinatário implícito da enunciação. 
lui, on est obligé de constater qu'il n'y a pas 'transmission', mais qu'au contraire, tout se passe comme si l'énonciataire voyait le tableau en lieu et place de l'énonciateur, ou 'dans son dos'. Il s'agit alor plus d'un 'vol' de la signification que d'un 'don'. (Fontanille, 1989; 13)

No caso de textos imagéticos, como o acima referido, fica evidente que a relação entre os sujeitos da comunicação (enunciador e enunciatário) se funda numa "substituição de instâncias". Fontanille cria um esquema comparativo para ilustrar tal diferença.

No esquema tradicional, que pressupõe a transmissão de um saber do enunciador para o enunciatário, teríamos a seguinte representação:

$$
\text { Enunciador } \rightarrow \text { Enunciado } \rightarrow \text { Enunciatário }
$$

No novo esquema proposto por Fontanille, a representação esquemática ficaria antes assim:

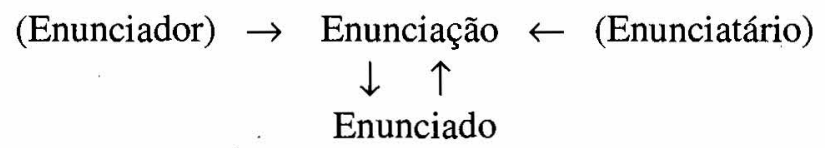

Este segundo esquema evidencia o jogo enunciativo como dependente' da construção e da`ocupação de espaços actanciais. Segundo o autor, "Quand la signification est 'mise en images' la relation entre sujets d'énonciation semble foundée sur une 'substituition d'instances' avec une évidence suffisante."

Para tal evidência, ao tratar da dimensão escópica, também chama a atenção Eric Landowski:

Como toda estrutura de comunicação, a que designa o verbo ver implica a presença de ao menos dois protagonistas unidos por uma relação de pressuposição recíproca - um que vê, o outro que é visto - e entre os quais circula o próprio objeto da comunicação, no caso a imagem que um dos sujeitos proporciona de si mesmo àquele que se encontra em posição de recebê-la. O fato de que os dois 
actantes entre os quais se efetua a transmissão da mensagem - aqui icônica ou, mais simplesmente, figurativa possam ora ser confundidos num único e mesmo ator, como no caso do 'narcisismo', em que o observador contempla o seu próprio reflexo, ora corresponder a dois atores distintos que dividem entre si os papéis de emissor e receptor (numa relação de comunicação, nesse caso, transitiva) não modifica em nada a organização da sintaxe inter-actancial subjacente, que, por definição, permanece indiferente às variações mais superficiais concernentes à organização do dispositivo actorial. (Landowski, 1992; 88-89)

\section{O ato e a instância da enunciação}

A comunicação parece estar implicada, assim, no próprio ato enunciativo e no enunciado por ele produzido. Como a articulação entre esses "lugares" referidos no esquema de Fontanille se dá não só no sentido horizontal mas também no vertical, convém se deter na noção de enunciação para melhor tentar explicitar tais relações.

A enunciação, depois que Benveniste (1966) distinguiu o eu/ aqui/agora do ele/lá/então do enunciado, pode ser entendida como uma instância lingüística logicamente pressuposta pela existência do enunciado. Mas, antes de ser tal instância, a enunciação é o ato que faz ser o enunciado. Esse ato, no entanto, não pode ser apreendido enquanto tal, só pode ser pressuposto a partir do seu próprio produto: $\mathrm{o}$ enunciado. Mas, para que tenha podido produzir o enunciado que produziu, esse ato enunciativo - a enunciação propriamente dita -, teve de mobilizar os significantes responsáveis pelo que figura no enunciado, e que se encontravam anteriormènte num local virtual: daí a imagem da tal instância a que nos referimos. O ato da enunciação e a instância da enunciação mantêm, assim, uma pressuposição recíproca.

Não obstante, diferentes concepções teóricas da enunciação costumam tender para um desses pólos. A teoria pragmaticista de Oswald Ducrot, por exemplo, procura enfatizar o ato enunciativo e, nele, a sua singularidade. Ducrot examinou as relações entre 
enunciação e enunciado, a partir das relações entre o dizer e o dito. Seria a partir do sentido efetivamente visado pelo dizer enunciativo que se poderia reconstituir o sentido do dito. Desse modo, descrever a significação de um enunciado é descrever sua enunciação, ou seja, propor uma representação do surgimento deste enunciado no contexto dado. A análise dos conectores, por exemplo, que Ducrot chama "mots du discours", consiste em evidenciar as relações que eles realizam não no nível das sequiências que conectam os significantes materiais no enunciado (o dito), mas sim as entidades semânticas logicamente reconstrutíveis a partir do enunciado (o dizer).

Tal concepção, no entanto, focalizada a partir da troca de atos ilocucionais ${ }^{10}$, situa-se na dimensão dita interproposicional, e permanece distanciada de uma teoria do discurso ${ }^{11}$ nos moldes greimasianos.

A semiótica greimasiana considera que o espaço das virtualidades semióticas, cuja atualização depende da enunciação, é "o lugar de residência das estruturas semio-narrativas" ${ }^{12}$, formas que,

10. Segundo Austin - filósofo da Escola de Oxford a quem se reporta Ducrot -, ao se enunciar uma frase qualquer, realizam-se simultaneamente três atos: um ato locutório (em que se articulam sons e se evocam noções representadas pelas palavras), um ato ilocutório (na medida que a simples enunciação da frase já constitui um certo ato, uma transformação das relações entre enunciador e enunciatário), e um ato perlocutório (na medida em que o enunciado serve a fins outros além daqueles literalmente enunciados). $\mathrm{O}$ ato ilocutório mereceu reparos do norte-americano Searle, de Cambridge, que procurou demonstrar que este ato é regido por regras constitutivas. Ou seja, mais do que normativas, essas regras são coercitivas em relação ao seu emprego, na medida em que encerram um certo compromisso por parte de quem as emprega. É nesse sentido que, para Searle, uma palavra é um ato ilocutório "quando ela tem por função, primeira e imediata, modificar a situação dos interlocutores" (apud Todorov e Ducrot, 1977).

11. Segundo Courtés $(1991 ; 59)$ Tout cet univers de la communication, de l'énonciation, de la pragmatique, a été déjà en partie exploré, specialement au niveau de la langue: en revanche, au plan du discours - qui met en jeu des contextes variables - la recherche en ce domaine n'a que fort peu progressé.

12. O Dicionário de Semiótica (s/d) oferece a seguinte explicação para o sentido de "estruturas narrativas": O fato de a teoria semiótica desenvolver-se de maneira progressiva e por vezes sinuosa não tem deixado de provocar certas confusões terminológicas. É o que acontece, por exemplo, com o conceito de narratividade que, aplicado de início unicamente à classe dos discursos figurativos (narrativas), revelou-se um princípio organizador de todo e qualquer discurso. A expressão 'estruturas narrativas' viu, com isso, transformar-se o seu conteúdo para 
ao se atualizarem como operações, constituem a competência semiótica do sujeito da enunciação"13. Este último é pressuposto pela singularidade do ato enunciativo, que revela que o enunciado que aí se apresenta é fruto de uma escolha (ou de uma determinação qualquer) feita na instância da enunciação e que, por isso, bem poderia ter sido outro não fosse a ação específica deste sujeito, que vem marcada espácio-temporalmente. É necessário, então, para que o sujeito da enunciação faça o que faz, que disponha de uma competência semiótica (de um poder e saber fazer). E, considerando isso, se poderia dizer agora que a enunciação é "o lugar de exercício da competência semiótica", e também o local onde emerge o sujeito da enunciação, que se situa no único lugar de onde é possível dizer eu/aqui/agora. Este lugar (o da enunciação) seria semioticamente vazio e semanticamente cheio, uma vez que se revela como uma espécie de depósito de sentido à disposição do sujeito da enunciação.

A passagem da enunciação para o enunciado se efetua graças a um procedimento denominado desembreagem que permite que se projete para fora desta instância tanto os actantes do enunciado quanto as coordenadas espaço-temporais (a pessoa, o espaço e o tempo, ou, em termos semióticos, o eu, o aqui, o agora). No entanto, isso só ocorre como simulacro; no enunciado o eu, aqui, agora da enunciação se convertem, de fato, no ele, lá, então. Ou seja, no enunciado o lugar da enunciação só se efetiva pela máscara da enunciação enunciada, que mascara um ele num " $e u$ ", um lá num "aqui", um então num "agora".

Mas, como o que nos é dado é sempre o enunciado, nunca a enunciação - sempre pressuposta -, o caminho que se faz inicialmente é inverso àquele que se apresentou acima e é levado a efeito pelo

designar finalmente, por oposição às estruturas discursivas, o tronco gerativo profundo, comum em principio a todas as semióticas e a todos os discursos, $e$ lugar de uma competência semiótica geral. Processa-se então uma substituição terminológica, mas lentamente: a expressão estruturas sêmio-narrativas substitui, pouco a pouco, a expressão 'estruturas narrativas' em sentido amplo.

13. Acreditamos, considerando a posição de Julia Kristeva ao situar a intertextualidade no genotexto, que as "importações" intertextuais são efetuadas pelo sujeito da enunciação e postas em jogo quando o nível semio-narrativo é por este mobilizado, no momento em que se articula o discurso. Ou seja, o sujeito da enunciação, na colocação em discurso, dispõe também de uma competência intertextual. 
mecanismo da embreagem. Esta permite que, a partir do enunciado dado, se tenha acesso, por pressuposição, ao lugar imagináriotranscendental da enunciação.

\section{Os papéis do enunciador e do enunciatário}

Para a semiótica greimasiana, a competência discursiva seria constituída por um conjunto de procedimentos capazes de instituir o discurso como um espaço e um tempo povoados de sujeitos; sujeitos que ao construírem o mundo como objeto, constroem-se a si mesmos. E é no nível da enunciação que a colocação em discurso (discursivisação) se efetua, depois, evidentemente, de mobilizadas as estruturas semio-narrativas em seu conjunto e de instaurado o sujeito da enunciação, do qual os sujeitos do enunciado não passam de delegados. Duas posições actanciais são, então, simultaneamente recobertas: a do enunciador e a do enunciatário.

Como se sabe, a semiótica explica a discursivisação desencadeada pela emergência do sujeito da enunciação e pela convocạção das estruturas actanciais - como nada mais sendo do que a sequiência ordenada de dois programas narrativos: um programa de performance: a manipulação; e um programa de competência: a operação.

O programa de performance, enquanto manipulação, põe em jogo dois sujeitos: o enunciador, enquanto sujeito do fazer-fazer, e o enunciatário, enquanto sujeito do fazer (o sujeito da enunciação recebe as duas posições actanciais).

A operação, enquanto programa de competência, visa somente a estabelecer as competências do sujeito; bem entendido, do sujeito do fazer-fazer e do sujeito do enunciado. O enunciatário, como observador, pode aceitar ou não os valores do enunciador. Ao não aceitar os valores convocados na manipulação ${ }^{14}$, o enunciatário se investe num anti-sujeito e pode questionar o enunciador.

14.Como se sabe (Courtés, 1991; 250), semioticamente a manipulação não implica nenhum investimento de valor moral, e pode ter duas formas: uma chamada positiva, da ordem do fazer fazer, outra negativa, da ordem do fazer não fazer. 
Assim, para que o enunciador faça o seu discurso é preciso que ele primeiramente convoque as estruturas semio-narrativas e que as assuma como sendo "suas". A convocação das estruturas semio-narrativas pode então ser concebida como o procedimento pelo qual o enunciador se identifica na enunciação enunciada ou identifica o seu destinador pressuposto. A discursivisação levada a efeito pelo enunciador-manipulador apresenta, no entanto, um limite. O programa de performance não chegaria a termo caso o discurso assim produzido não fosse assumido também pelo enunciatário, e não somente pelo enunciador. Para que isso venha ocorrer, no entanto, é preciso que o enunciatário reconheça o discurso apresentado como um discurso dotado de valores que possa aceitar. Isso quer dizer que os componentes discursivos pertencentes à instância da enunciação dependem da realização não apenas de um, mas de dois conjuntos de estruturas semio-narrativas atualizadas: a do enunciador e a do enunciatário.

E como, por definição, esses dois conjuntos de estruturas atualizadas não podem ser idênticos (se assim fosse eles seriam o mesmo), a manipulação (do destinador) só os faz parecer iguais, e a interpretação (do destinatário), embora potencialmente possa situar de onde "fala" o enunciador, sempre deixa escapar algo. Mas, sem dúvida, as estruturas mobilizadas pelo jogo comunicacional apresentam um limite bem definido: elas nunca podem ser contraditórias, sob pena de invalidar o lance, muito embora esse jogo tolere e se constitua pela assimetria.

Disso decorre que, para poder ser aceitável tanto pelo enunciador quanto pelo enunciatário, o discurso deverá resultar de um contrato, de um compromisso, mesmo que tácito, entre ambos. Além disso, por mais mentiroso que possa ser, na tentativa de manipular pela mentira o enunciatário, ou seja, de tentar não cumprir o contrato firmado, que sempre pressupõe a verdade, o discurso enunciado não pode deixar de realizar aspectos do nível profundo das estruturas semio-narrativas de seu enunciador e, desse modo, deixar marcas "verdadeiras" de sua enunciação, uma vez que esta encontra-se comprometida com linguagens que escapam ao domínio do enunciador. Ao contrário disso, as estruturas semio-narrativas do 
enunciatário não têm senão, quando focalizadas do ponto de vista do enunciador, o estatuto do poder ser, do possível: o enunciatário e sua competência são sempre pressupostos pelo enunciador. $\mathrm{O}$ que quer dizer que algo na comunicação, que é mediada no nível dessas estruturas, sempre escapa, por mais minucioso que seja o referido contrato ${ }^{15}$.

As relações semióticas entre os actantes enunciador/ enunciatário se efetuam a partir do momento em que eles, sincretizados, assumem o "percurso temático da produção", ou, quando polarizados, recobrem o "percurso da comunicação"16. $\mathrm{E}$ é exatamente na imbricação desses dois eixos que a enunciação e a comunicação se confundem e se pode vislumbrar, como o fazemos neste trabalho, uma equivalência possível entre elas: não há produção sem o ato enunciativo, e a comunicação nasce desse mesmo ato, do qual não passa, se nos for permitido usar uma imagem, de uma espécie de expansão, ou de um certo deslocamento no sentido horizontal (a produção, por sua vez, seria um deslocamento do ato enunciativo no sentido vertical).

O sincretismo enunciador/enunciatário, que caracteriza o tema da produção, evidencia, segundo Barros (1988), a cumplicidade necessária entre enunciador e enunciatário para que o sentido seja produzido no discurso, por vias dos programas narrativos de

15. Nem sempre, porém, é possível estabelecer uma base contratual; diz-se, então, que se estabelece uma relação polêmica entre enunciador e enunciatário. Landowski, examinando a questão da confiança entre enunciador e enunciatário, se interroga para melhor poder situá-la: "Que significa isso mais profundamente senão que a palavra dada na promessa ou no juramento, longe de selar uma harmonia preestabelecida entre os respectivos programas das partes, intervém num contexto essencialmente polêmico, no interior do qual a divergência, sempre latente, dos interesses perseguidos por cada um funda, antes de qualquer outra coisa, uma legitima desconfiança entre os sujeitos?" (1992; 159)

16. Inspirada neste "achado" de Greimas, Barros (1988; 136 e s) o vincula a um exame canônico da narratividade para estabelecer a economia da enunciação. Considera, então, o enunciador e o enunciatário como papéis temáticos discursivos nos quais se distinguem papéis temáticos e actantes narrativos: "Os papéis temáticos de enunciador e de enunclatário constituem, na verdade, uma espécie de neutralização de dois percursos temáticos, da mesma configuração de 'enunciação: o de produção e o de comunicação (...) Reservam-se os papéis de enunciador e enunciatário para o percurso temático da comunicação (quem comunica e quem recebe e interpreta a comunicação) e emprega-se o de sujeito da enunciação, sincretismo de enunciador e enunciatário, no percurso da produção (quem produz)." 
construção, que são de duas espécies: programas de construção do sujeito e programas de construção do objeto. Os primeiros dizem respeito ao modo de o- sujeito entrar em conjunção com os objetovalọ, que pode ser por doação, por apropriação ou por troca. Já nos programas de construção do objeto, este aparece como suporte de valores de que um sujeito deseje ou necessite, para satisfazê-lo ou suprir, se se quiser, uma necessidade, seja de ordem cognitiva, pragmática ou patêmica. Por exemplo: "o objeto-discurso é um objeto de valor cognitivo; um bolo, um objeto de valor pragmático; um presente, um objeto de valor afetivo". A partir da construção (performance) dos objetos (sejam eles pragmáticos, cognitivos ou patêmicos) é que se pode avaliar, por presssuposição, a competência do sujeito da enunciação.

Como produtor do discurso, o sujeito da enunciação trabalha em obediência a um destinador-manipulador, que pode ser figurativizado no texto como um personagem, ou ser apenas pressuposto quando o sujeito do enunciado age movido por valores sóciohistóricos. Isso quer dizer que sua autonomia é limitada ao fazer, sendo os valores determinados de antemão pelo destinador.

Determinar os destinadores do sujeito da enunciação corresponde a inserir o texto no contexto de uma ou mais formações ideológicas, que lhe atribuem, no fim das contas, o sentido. (Barros, 1988; 141)

No percurso temático da comunicação, o enunciador desempenha o papel de destinador-manipulador e fica responsável pelos valores em jogo e pretende levar o enunciatário a crer e a fazer. Ou seja, desenvolve um fazer persuasivo a fim de manipular cognitiva e pragmaticamente o destinatário, que, por sua vez, realiza, quando devidamente manipulado, um fazer interpretativo do discurso posto em cena.

Se tanto o fazer persuasivo do enunciador quanto o fazer interpretativo do enunciatário se realizam no e pelo discurso, concluise que para conhecer e explicar tais fazeres e por meio deles apreender a instância da enunciação, precisa-se proceder à análise interna e imanente do texto (Barros, 1988;137). 
Isso evidencia o caráter manipulador do discurso comunicativo. Ou seja, embora se apresente como um discurso que quer fazer saber, na verdade o que realiza, pelo menos como um ponto de partida necessário, é uim fazer crer (do enunciador) que requer como correlato um acreditar (do enunciatário).

Na chamada comunicação cotidiana, na qual os valores que o enunciador mobiliza têm fins predominantemente persuasivos, antes de serem racionalmente argumentativos, isso fica bastante evidente. Mas aí

é preciso admitir a existência de dois níveis de funcionamento do 'crer' e sua relativa autonomia: crer (ou não crer) no que diz alguém é uma coisa; crer (ou não crer) naquele que diz alguma coisa é outra (Landowski,1992; 154).

Ou seja, crer no que diz o enunciado é coisa diferente de crer na autoridade do enunciador. No primeiro caso, subordina-se à lógica; no segundo, à confiança em que se deposita no enunciador.

\section{Comunicação e produção do sentido}

O eixo da comunicação distingue-se claramente do eixo da produção. A semiótica greimasiana atribui ao primeiro um sentido horizontal, sintagmático, com o enunciador e o enunciatário localizados em extremidades opostas, que pode ser assim representada:

Eixo da comunicação

Já o eixo da produção articularia sujeito e objeto, e teria um sentido vertical, paradigmático; sua manifestação se daria com o sincretismo do enunciador-enunciatário que é representado, nesta teoria, pelo sujeito da enunciação: 
Eixo da produção

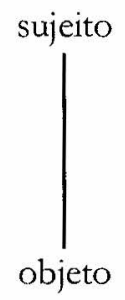

Embora a semiótica greimasiana vincule cada um desses dois eixos a domínios diferenciados - transcendente (horizontal) e imanente (vertical) -, podemos atribuir, se retomarmos a partir deste esquema as concepções de diálogo e ambivalência, que Julia Kristeva (1974) tomou de empréstimo a Mikhail Bakhtin 1992), ao eixo da comunicação (horizontal) o diálogo, e ao eixo da produção (vertical), a ambivalência. Com isso estabelecido, haveria um ultrapassamento do nível imanente por parte do eixo vertical, que passaria a contar em suas extremidades não mais com o par sujeito/ objeto, mas sim com o par texto/contexto:

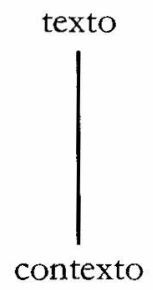

A partir da sobreposição entre os eixos horizontal e vertical fica fácil perceber que não há propriamente um abismo entre o eixo da comunicação e o eixo da produção, como sugere a leitura que Kristeva enfatiza ao atribuir toda importância à produtividade, que ocorre, enquanto semiose ilimitada, no eixo da produção, e apenas faz emergir, por obra da significância, sua "faceta superficial" no eixo da comunicação.

O que valorizamos, aqui, é justamente a importância desta emergência, essa contingência, sem a qual a produtividade que se dá no eixo vertical seria inacessível. 
Podemos, talvez, melhor perceber a aproximação do eixo da produção com o eixo da comunicação ao imaginar inicialmente um encurtamento gradativo do eixo horizontal; desse modo, os elementos polarizados, enunciador e enunciatário, tendem a se aproximar do eixo vertical, até se condensarem num ponto deste cruzamento. Uma sobreposição como essa pode ser vislumbrada na manifestação enunciada, que pode ser entendida como um ponto que se dá no cruzamento desses eixos. E seria, mesmo, a partir desse ponto - representado abaixo como um círculo ovalado - que se efetuariam os deslocamentos em sentido horizontal (e teríamos a comunicação) ou em sentido vertical (e teríamos a produção), conforme o esquema:

Sobreposição dos eixos na manifestação

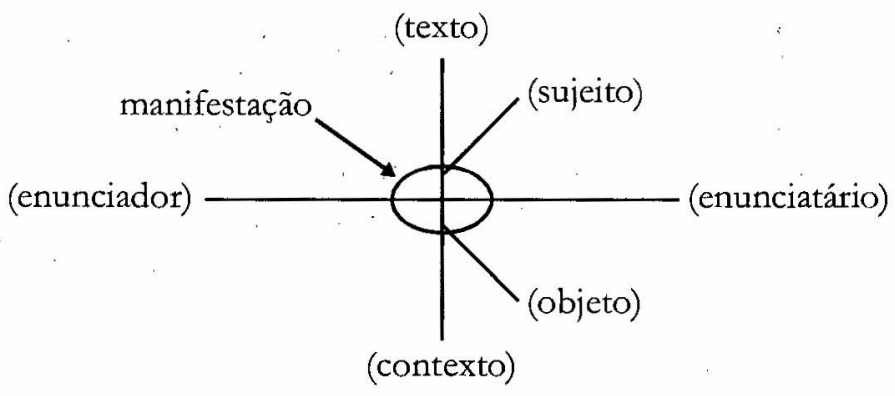

deslocamento vertical a partir da manifestação = eixo da produção deslocamento horizontal a partir da manifestação $=$ eixo da comunicação

A manifestação textual seria, então, segundo nossa hipótese, a superfície visível por meio da qual se pode pressupor tanto as relações de produção, que se dão em profundidade, no eixo vertical, quanto as de comunicação, que se dão horizontalmente. Ambos os eixos vêm à luz, por vias de seus traços, graças à mobilização efetuada pelo ato enunciativo-comunicacional que faz brilhar, no instante da semiose, o sentido, que se constitui na novidade-comprometida e vivenciada, se assim podemos dizer, que cada texto traz. 


\section{Bibliografia}

BARROS, Diana L. P. 1998. Teoria do Discurso - Fundamentos Semióticos. São Paulo: Atual.

BAKHTIN, M. 1981. Problemas da Poética de Dostoiévski. Rio de Janeiro: Forense Universitária.

. 1992. Estética da Criação Verbal. São Paulo: Martins Fontes.

BENVENISTE, E. 1966. Problémes de Linguistique Générale. Paris: Gallimard.

COURTÉS, Joseph .1991. Analyse Sémiotique du Discours - De l'Énoncé à l'Énonciation. Paris: Hachette.

DUCROT, Oswald .1977. Princípios de Semântica Lingüística Dizer Não Dizer. São Paulo: Cultrix.

FONTANILLE, Jacques. 1989. Les Espaces Subjectifs Introduction à la Sémiotique de l'Observateur. Paris: Hachette.

FREITAS, Jeanne Marie. 1992. Comunicação e Psicanálise. São Paulo: Escuta.

GREIMAS A. J.; COURTÉS, J. 1979. Sémiotique - Dictionnaire Raisonné de la Théorie du Langage I. Paris: Hachette.

1986. Semiotique - Dicitionnaire Raisonnée de la Théorie du Langage II. Paris: Hachette

HJELMSLEV, Louis. 1975. Prolegômenos a uma Teoria da Linguagem. São Paulo: Perspectiva.

JAKOBSON, Roman. 1969. Lingüística e Comunicação. São Paulo: Cultrix.

KRISTEVA, Julia. 1974. Introdução à Semalálise. São Paulo: Perspectiva.

LÉVI-STRAUSS, C. 1976. A Noção de Estrutura em Etnologia, in Os Pensadores. São Paulo: Abril.

LANDOWSKI, E. (1992) A Sociedade Refletida. São Paulo: EDUC/ Pontes.

MERLEAU-PONTY, M. 1991. Signos. São Paulo: Martins Fontes.

TODOROV, J. e DUCROT, O. 1977. Dicionário Enciclopédico das Ciências da Linguagem. São Paulo: Perspectiva. 